\title{
Young Blood Rejuvenates Old Bodies: A Call for Reflection when Moving from Mice to Men
}

\author{
Bjørn Hofmann ${ }^{a, b}$ \\ ${ }^{a}$ The Centre of Medical Ethics, University of Oslo, Oslo, Norway; \\ ${ }^{\mathrm{b}}$ Institute for the Health Sciences at the Norwegian University of Science and Technology, Gjøvik, Norway
}

\section{Keywords}

Parabiosis - Justice · Reproductive rights · Rejuvenation · Humoral pathology

\section{Summary}

Connecting the circulatory system of old and young mice (parabiosis) is documented to have rejuvenating effects on cells, tissues, organs, and functions. A wide range of benefits are envisioned. Blood-based rejuvenation can come to totally change population health and aging. The first blood rejuvenation studies on humans with Alzheimer's disease have started. It puts blood at the center of therapy and revitalizes the historical line of humoral pathology from Hippocrates and Harvey, creating a new type of 'bloodletting.' However, moving from mice to men requires careful consideration. Parabiosis actualizes wellknown ethical challenges, such as just distribution of health care, avoiding disparities, and providing equal access to health care resources, as well as issues of human enhancement. However, it also poses new problems. Using internal substances in some persons as means to rejuvenate others calls for ethical reflection. New type of 'blood bonds' may result from the continuous demand for specific types of blood. Even if rejuvenating substances from blood may be artificially and cheaply produced and justly distributed, problems arise: survival may have to be balanced against reproduction, as reproductive age increases. Eternal youth and endless bliss have always been vital human dreams. Although parabiosis may bring us closer to the fountain of youth than ever, it is still too early to provide full-fledged assessments of its implications or to foresee how it will change health, aging, medicine, and society. However, in order to bring our reflective abilities on par with our technical skills, we need to start reflection now.

(C) 2018 S. Karger GmbH, Freiburg

\section{Introduction}

By connecting the circulatory system of young and healthy mice to old and sick mice, the young blood tends to bring new life to the organs of the old. They become healthier, stronger, and smarter [1]. The method, parabiosis, was described by Paul Bert already in 1864 and gained significant attention during the 19601970s [2]. After falling out of the scientific limelight, recent experiments [1,3-13] have resulted in a race to identify the 'elixir of life' in blood [14]. By now, young blood has been shown to have a rejuvenating effect on the metabolic [15] and cardiovascular systems [4], on muscles [8], on the aging brain $[3,7]$, and on brain functions $[3,10,12,16]$ in mice. Research is now moving from mice to men [17], and, if successful, the results will totally change medicine. It will revitalize humoral pathology and invigorate the role of blood - not only for diagnostics but also for treatment. The humoral line from Hippocrates over Harvey will culminate in making the alchemists' dream come true. But, by identifying the 'fountain of youth' within us, a range of crucial ethical challenges emerge.

\section{The Biology of Blood Rejuvenation}

In 2008, the research group at Stanford first reported that parabiosis between old and young mice restored muscle and liver cells in the old mice [5] and related the rejuvenation of muscle cells to factors promoting cell division (Notch signaling) and to deactivating factors blocking cell division (transforming growth factor; TGF) [18]. In 2014, the group identified oxytocin as an age-modifying factor in blood [19]. More recently, human cord plasma treatment is found to revitalize the hippocampus and improve cognitive function in aged mice [16]. A research group at Harvard identified the growth differentiation factor 11 (GDF-11) as the humoral factor responsible for rejuvenating effects in muscles, blood

\section{KARGER}

() 2018 S. Karger GmbH, Freiburg

Fax +497614520714 
vessels, and neurons of the brain $[3,4,13]$. These results have been disputed as the tests and reagents used by the Harvard group were found not to be precise enough $[8,20]$.

Identifying rejuvenating factors in human blood has resulted in significant optimism for finding simple and affordable treatments for age-related diseases [21]. However, so far, no convincing results have been presented, and no consensus on mechanisms or implications exists $[10,14,20,22]$. Data on transfusions from younger donors does not show results on survival rates of older patients [23]. Reproduced results are scarce, and more knowledge is needed before the 'lapis philosophorum' makes its way from bench to bed. Fortunately, this gives some leeway to reflect on the ethical issues posed by the groundbreaking prospects.

\section{Invigorating Existing Challenges: Therapy versus Enhancement}

Some of the challenges posed by blood rejuvenation are not new. The difficulty with drawing the line between treatment and enhancement are well known from other areas, e.g., ordinary drugs used in sports to enhance performance (steroids, modafinil, meldonium) and memory-enhancing drugs developed for persons with cognitive impairment, but used by students before exams [24-26].

Promotors of human enhancement, so-called transhumanists, argue that there is no distinct difference between enhancement and therapy [27] and that therapy is a special case of enhancement [28]. On the other hand, it is argued that we can differentiate between i) restorative or preventive, non-enhancing interventions, ii) therapeutic enhancements (allowing for better performance than before disease or impairment), and iii) non-therapeutic enhancements [29]. These debates hinge on the profound philosophical questions on 'what is natural?' and 'what is normal?' No doubt, the distinctions between therapy and enhancement may become crucial if blood has the prospective rejuvenating properties. However, there is a presumption that youth is good and that more is better [30]. As highlighted in myths and arts, this is not obvious: Titonus obtained eternal life, but found it meaningless. Virginia Wolfs Orlando lived for 400 years but found it toiling. Bowerick Wowbagger in Douglas Adams' Hitchhiker's Guide to the Galaxy, lives eternal but is unhappy.

\section{Making Aging a Disease}

Correspondingly, parabiosis fuels the debate on whether aging is a disease that should be treated [31-38]. It is well known that conditions that were previously not considered to be diseases (alcoholism, infertility, attention deficit), turn into diseases when they become treatable [39] and that there is a drive for conditions to be treated if they can be treated, i.e., there is an imperative of possibility [40]. Accordingly, blood rejuvenation may fuel the process of making aging a treatable disease, increasing the population growth, and generating a wide range of other downstream problems. Increasing the old population in need of rejuvenating blood enhances the challenge with provision and access.

\section{Access and Disparities}

Blood rejuvenation therefore actualizes the question of how to manage scarce biological resources (blood), which are well known from transplantation debates. However, while there is a lack of solid organs for transplantation (one kidney for several hundreds of recipients), there are many healthy volunteers registered as potential stem cell donors (allowing for almost perfect matches in the majority of patients). With the healing and rejuvenating effect of blood, the need for solid organ transplantation may also come to be reduced considerably.

Nevertheless, providing enough rejuvenating blood and setting limits to blood rejuvenation can come to be challenging. Although only few rely on the market to encourage and ensure access [41], it is far from obvious that subscribing to invisible hands or regulated markets will solve the access and distribution problem. Although synthetic rejuvenating factors may meliorate the problem, the basic problem (justice) pertains: how to avoid that only the affluent have access (and thereby enhancing disparities)?

The harm principle may also be relevant as parabiotic disease and accumulation of iron and development of antibodies against blood products are well-known harms [42]. So are transfusion-transmitted infections. Unknown long-term risks may of course appear.

In addition to actualizing and aggravating existing challenges, parabiosis also poses new problems.

\section{New Problems: 'Blood Flow' and 'Blood Bonds'}

Parabiosis raises the question of (inter)dependency. Even where rejuvenation would not require that people are directly connected, it would generate ties between those giving and those demanding blood. A person may come to need blood (products) from a limited set of donors, making ordinary risk- and resource-spreading approaches (as with insurance) less relevant. Specific blood types may only be obtained from a limited group of people, and the expected demand for rejuvenation would bust today's measures for providing specific blood groups ( $\mathrm{O}$ and $\mathrm{Rh}$-negative blood). New types of 'blood bonds' may thus emerge.

Additionally, there are valid concerns that the blood will not flow from affluent youth in developed countries to the elderly, poor, and frail in developing countries. On the contrary, we may expect the demand for rejuvenating blood in the affluent part of the world to be so strong and the needs for resources in the developing world to be so profound that buying and selling blood becomes an irresistible option. Even more, in the case that (only) blood or blood components of young persons would be able to contribute to rejuvenation, we will have to face with problems with consent, with avoiding exploitation, and with averting two-class health systems. 
Thus, in addition to concerns that parabiosis will extend traditional challenges with providing just and equal access, emerging 'blood bonds' may generate a unidirectional blood flow enhancing existing or creating new disparities, dependencies, and exploitations.

\section{The Fountain of Youth within Us}

Noteworthy, exploited natural resources such as gold and oil have often been external to human beings, but now they may become internal. Previously people worked in factories, now they may become factories. No doubt, biological material has been conceived of as waste or natural resources previously [43], but that was mainly excess material such as tissue samples and removed tumors. Hence, the rejuvenating effect of blood may result in a commodification of blood and disrupt well-established traditions of altruismbased donation, undermining the well-established organization of blood donation. It may also render traditional labor theories inadequate, as unifying blood and toil does not necessarily reduce sweat and tears, to paraphrase Winston Churchill [44].

Therefore, blood rejuvenation may bust the traditional gift metaphor [45] so prominent in present-day non-remunerated blood donation. If 'the fountain of youth' is filled with blood, strong forces will make it flow into the market as a commodity. Plasma donors are paid in the US, so why not whole blood donors? On the other hand, it may of course evoke a new type of altruism as the possibility of helping people expands. Giving blood may directly influence the welfare of specific persons, and blood is a renewable substance. At the same time, rejuvenating others may increase the global population and thereby reduce the available resources (food, energy, wealth, health) for each individual - increasing the burden of disease and disparities. Which of these scenarios is the most likely commercialization, enhanced altruism, self-restricting altruism, or other scenarios- and how we should decide to direct the development will of course depend on how exactly blood is rejuvenating. In any case the matter will need careful reflection and deliberation.

With the production of synthetic rejuvenating factors, the problems with dependency and availability might be resolved, but the problems with access and allocation may reside. Who should get rejuvenation? How should we acquire the necessary resources? How should we handle rejuvenation for extended living? If more QALYs can be obtained by blood rejuvenation than by treating certain diseases, why bother with the diseases? This adds new dimensions to the priority setting problem. Even if rejuvenating substances from blood may be artificially and cheaply produced and justly distributed, problems arise with an increasing population.

\section{Longevity versus Reproduction}

Hence, a new basic challenge arises: How should we balance evolutionary goals, such as survival versus reproduction? Will longevity and the following extended 'reproductivity' urge regulation? Living longer may extend individuals' reproductive periods and results in an increased number of relationships accompanied with strong desires to have offspring. However, reproduction may have to be restricted when the number of offspring may come to challenge sustainable access to basic resources, such as food and housing. 'You cannot have more children when you live longer' or 'either you live long or you have children.' Rejuvenation may therefore challenge present procreative rights and liberties. However, most attempts to regulate people's reproduction (or lifespan) pose profound ethical challenges. Also for the individual it may be difficult to balance survival and reproduction.

No doubt, survival has trumped reproduction before, e.g., during war and famine. However, rejuvenation appears to occur in the other end of the spectrum, in abundance and not in scarcity. Then, it is an open question whether people will (or should) choose survival over reproduction. Leaving it to self-regulation may lead to substantial inequalities, while regulating reproduction (and lifespan) is challenging.

\section{Changing History}

A rejuvenating effect of parabiosis will revitalize humoral pathology. Blood rejuvenation connects to the teaching of the four bodily fluids ascribed to Hippocrates of Cos (460-370 BC), the 'discovery' of the circulatory system by William Harvey (15781657), and 2000 years of bloodletting. But it does much more: It makes blood 'the elixir of life', the 'philosopher's stone', [14], and 'the fountain of youth'. While the humoral pathology of Hippocrates and the circulatory discoveries of Harvey aimed at understanding, avoiding, and treating disease, rejuvenation will incite a new type of 'bloodletting'. If this is anything more than a mere hype, we need to assure responsible research, implementation, and use and to avoid new and disastrous forms of 'bloodshed'.

\section{Changing Medicine}

Blood rejuvenation will undoubtedly change medicine. Not only may we get a new and powerful tool for preventing and treating a wide range of devastating diseases. We may also get unprecedented possibilities to extend life. Hence, the goal of medicine may move from avoiding suffering and pain to promoting health, youth, and wellbeing as the distinction between treatment and enhancement will wane. Whether any form of parabiosis will have the promised effects is of course highly speculative; however, altering the goal of medicine obviously calls for fundamental and enduring reflection.

\section{Changing Research}

While we are on the way to find out whether parabiosis may have such rejuvenating effects, we face with some challenging questions, e.g., 'How should we regulate risk in rejuvenation re- 
search?'. Risk exposure is usually justified by potential reduction in pain and suffering, but rejuvenation goes beyond pain reduction. Parabiotic disease, accumulation of iron, and development of antibodies against blood products have been mentioned [42] as well as transfusion-transmitted infections. Should research on parabiosis be barred because of its potential (high) risk, and, if balanced against the benefit of rejuvenation, how should this benefit be assessed? The question of how to balance risk against potential rejuvenation benefits covers new ground. Parabiosis, cell therapies, and other experimental treatments lack well reflected regulation, as do other forms of human enhancement [28]. Codes of research ethics aim at restoring and not enhancing health. It has been argued that it is easier for human beings to assess what is bad than what is good [46]. Therefore, we may be more troubled with assessing the benefits of rejuvenation than avoiding and treating actual ailments. Here we run into basic philosophical issues of 'what is a good life'.

\section{Summary and Conclusion}

The recent discoveries of tissue rejuvenation related to transfer of blood from young donors do potentially open completely new and science-fiction-like treatment and enhancement options. If real, it will totally change medicine, sparking a new zenith for humoral pathology (neo-humoral pathology) and giving new meaning to 'bloodletting'. It is yet far too early to say whether parabiosis will actually work or whether it is just another hype. Nevertheless, we need to start reflection now, as our technical abilities by far appear to outrun our reflective and ethical abilities. No doubt, parabiosis invigorates a wide range of existing challenges, such as just distribution of health resources, avoiding disparities, and distinguishing between treatment and human enhancement. However, it also poses new problems, such as creating new 'blood bonds' between donors and recipients, internalizing natural resources, and making human beings factories of 'the elixir of life', altering or sparking new forms of altruism in blood donation, challenging reproductive rights, and regulating risks and benefits in rejuvenation research.

Eternal youth and endless bliss have always been vital human dreams. Promising parabiosis research indicates that we may come closer to these dreams than ever. It is yet too early to foresee how parabiosis will move from bench to bed. The life-renewing philosopher's stone may turn out to be as hard to find in blood as elsewhere. Although it is far too early to assess the implications for clinical practice, for health policy, and for society, we should start our reflections on filling the holy grail with blood now, before our technical skills outpace or dominate our deliberations.

\section{Acknowledgment}

I am most thankful for valuable comments and advice from the editor and reviewers. Part of this work has been supported by Naturalness in Human Cognitive Enhancement Czech-Norwegian Research Program CZ09, project number 7F14236.

\section{Disclosure Statement}

The author has no conflicts of interest to disclose.

\section{References}

1 Scudellari M: Ageing research: blood to blood. Nature 2015;517:426-429.

2 Rosse C: Migration of long-lived lymphocytes to the bone marrow and to other lymphomyeloid tissues in normal parabiotic guinea pigs. Blood 1972;40:90-97.

3 Katsimpardi L, Litterman NK, Schein PA, Miller CM, Loffredo FS, Wojtkiewicz GR, Chen JW, Lee RT, Wagers AJ, Rubin LL: Vascular and neurogenic rejuvenation of the aging mouse brain by young systemic factors. Science 2014;344:630-634.

4 Loffredo FS, Steinhauser ML, Jay SM, Gannon J, Pancoast JR, Yalamanchi P, Sinha M, Dall'Osso C, Khong D, Shadrach JL, Miller CM, Singer BS, Stewart A, Psychogios N, Gerszten RE, Hartigan AJ, Kim MJ, Serwold T, Wagers AJ, Lee RT: Growth differentiation factor 11 is a circulating factor that reverses age-related cardiac hypertrophy. Cell 2013;153:828-839.

5 Conboy IM, Conboy MJ, Wagers AJ, Girma ER, Weissman IL, Rando TA: Rejuvenation of aged progenitor cells by exposure to a young systemic environment. Nature 2005;433:760-764.

6 Ferenbach D, Xin C, Wilflingseder J, Hughes J, Bonventre J: Impact of a young parabiotic circulation on renal injury and fibrosis in aged mice. Lancet 2016; 387:S42.

7 Dieguez D Jr: Young blood revitalizes the aging brain http://brainblogger.com/2014/06/13/young-blood-revitalizes-the-aging-brain/ (last accessed December 18, 2017).
8 Egerman MA, Cadena SM, Gilbert JA, Meyer A, Nelson HN, Swalley SE, Mallozzi C, Jacobi C, Jennings LL, Clay I: Gdf11 increases with age and inhibits skeletal muscle regeneration. Cell Metab 2015;22:164-174.

9 Castellano JM, Kirby ED, Wyss-Coray T: Blood-borne revitalization of the aged brain. JAMA Neurol 2015;72: 1191-1194.

10 Bouchard J, Villeda SA: Aging and brain rejuvenation as systemic events. J Neurochem 2015;132:5-19.

11 Al-Dabbagh S, McPhee JS, Murgatroyd C, ButlerBrowne G, Stewart CE, Al-Shanti N: The lymphocyte secretome from young adults enhances skeletal muscle proliferation and migration, but effects are attenuated in the secretome of older adults. Physiol Rep 2015;3: pii: e12518.

12 Villeda SA, Plambeck KE, Middeldorp J, Castellano JM, Mosher KI, Luo J, Smith LK, Bieri G, Lin K, Berdnik D, Wabl R, Udeochu J, Wheatley EG, Zou B, Simmons DA, Xie XS, Longo FM, Wyss-Coray T: Young blood reverses age-related impairments in cognitive function and synaptic plasticity in mice. Nature Med 2014;20:659-663.

13 Sinha M, Jang YC, Oh J, Khong D, Wu EY, Manohar R, Miller C, Regalado SG, Loffredo FS, Pancoast JR, Hirshman MF, Lebowitz J, Shadrach JL, Cerletti M, Kim MJ, Serwold T, Goodyear LJ, Rosner B, Lee RT, Wagers AJ: Restoring systemic gdf11 levels reverses age-related dysfunction in mouse skeletal muscle. Science 2014;344:649-652.
14 Sun H, Wang Y: The elusive philosopher's stone in young blood. Circ Res 2015;117:906-908.

15 Salpeter SJ, Khalaileh A, Weinberg-Corem N, Ziv O, Glaser B, Dor Y: Systemic regulation of the age-related decline of pancreatic beta-cell replication. Diabetes 2013;62:2843-2848.

16 Castellano JM, Mosher KI, Abbey RJ, McBride AA, James ML, Berdnik D, Shen JC, Zou B, Xie XS, Tingle M: Human umbilical cord plasma proteins revitalize hippocampal function in aged mice. Nature 2017;544: 488-492.

17 Sha S: The PlasmA for Alzheimer SymptoM Amelioration (PLASMA) Study. https://clinicaltrials.gov/ct2/ show/NCT02256306 (last accessed December 18, 2017).

18 Carlson ME, Hsu M, Conboy IM: Imbalance between psmad 3 and Notch induces CDK inhibitors in old muscle stem cells. Nature 2008;454:528-532.

19 Elabd C, Cousin W, Upadhyayula P, Chen RY, Chooljian MS, Li J, Kung S, Jiang KP, Conboy IM: Oxytocin is an age-specific circulating hormone that is necessary for muscle maintenance and regeneration. Nat Commun 2014;5:4082.

20 Smith SC, Zhang X, Zhang X, Gross P, Starosta T, Mohsin S, Franti M, Gupta P, Hayes D, Myzithras M: Gdf11 does not rescue aging-related pathological hypertrophy. Circ Res 2015;117:926-932.

21 de Magalhães JP, Stevens M, Thornton D: The business of anti-aging science. Trends Biotechnol 2017;35): 1062-1107 
22 Laviano A: Young blood. N Engl J Med 2014;371:573575.

23 Edgren G, Ullum H, Rostgaard K, Erikstrup C, Sartipy U, Holzmann MJ, Nyren O, Hjalgrim H: Association of donor age and sex with survival of patients receiving transfusions. JAMA Intern Med 2017;177:854-860.

24 Barco A, Pittenger C, Kandel ER: CREB, memory en hancement and the treatment of memory disorders: Promises, pitfalls and prospects. Expert Opin Ther Targets 2003;7:101-114.

25 Dekkers W, Rikkert MO: Memory enhancing drugs and Alzheimer's disease: enhancing the self or preventing the loss of it? Med Health Care Philos 2007; 10:141-151.

26 Lanni C, Lenzken SC, Pascale A, Del Vecchio I, Racch M, Pistoia F, Govoni S: Cognition enhancers between treating and doping the mind. Pharmacol Res 2008;57: 196-213.

27 Savulescu J, ter Meulen R, Kahane G: Enhancing Human Capacities. New York, Wiley \& Sons, 2011.

28 Bostrom N, Sandberg A: Cognitive enhancement: Methods, ethics, regulatory challenges. Sci Eng Ethics 2009;15:311-341.

29 Coenen C, Schuijff M, Smits M: The politics of human enhancement and the European Union; in Savulescu J, ter Meulen R, Kahane G (eds): Enhancing Human Capacities. London, Blackwell Publishing, 2011, pp 521535 .
30 Hofmann B: Limits to human enhancement: nature, disease, therapy or betterment. BMC Med Ethics 2017; 18:56

31 De Winter G: Aging as disease. Med Health Care Philos 2015;18:237-243

32 Caplan AL: Death as an unnatural process. Why is it wrong to seek a cure for aging? EMBO Rep 2005;6 Spec No:S72-75.

33 Evans JG: Ageing and disease. Ciba Foundation Sym posium 1988;134:38-57.

34 Gems D: Tragedy and delight: the ethics of decelerated ageing. Philos Trans R Soc Lond B Biol Sci 2011;366: 108-112.

35 Izaks GJ, Westendorp RG: Ill or just old? Towards a conceptual framework of the relation between ageing and disease. BMC Geriatr 2003;3:7.

36 Lawler DF: The changing understanding of ageing. Part 3: diseases of ageing. Vet Ital 2011;47:255-269.

37 Schramme T: 'I hope that I get old before I die': AGEING and the concept of disease. Theor Med Bioeth 2013;34:171-187.

38 Wareham CS: What is the ethics of ageing? J Med Eth 2017; doi: 10.1136/medethics-2017-104374.
39 Hofmann B: Technological invention of disease; in Carayannis E (ed): Encyclopedia of Creativity, Invention, Innovation and Entrepreneurship New York, Springer, 2013, pp 1786-1796.

40 Hofmann B: Is there a technological imperative in health care? Int J Technol Assess Health Care 2002;18: 675-689.

41 Radcliffe-Richards J, Daar A, Guttmann R, Hoffenberg R, Kennedy I, Lock M, Sells R, Tilney N: The case for allowing kidney sales. Lancet 1998;352:1950-1952.

42 Chute RN, Sommers SC: Hemolytic disease and polycythemia in parabiosis intoxication. Blood 1952;7: 1005-1016.

43 Solbakk JH, Holm S, Hofmann B (eds): The Ethics of Research Biobanking. New York, Springer, 2009, pp 363.

44 Langworth R: Churchill by Himself: The Definitive Collection of Quotations. London, PublicAffairs, 2011.

45 Titmuss R: The Gift Relationship: From Human Blood to Social Policy. London, New Press, 1970.

46 Tranøy KE: Asymmetries in ethics. Inquiry 1967;10: 351-372. 